\title{
Cocrystals of Barbituric Acid with Alkali Metal Halides
}

\author{
William Clegg, ${ }^{1, *}$ Gary S. Nichol, ${ }^{1,2}$ Ashish Patel ${ }^{1}$
}

\footnotetext{
${ }^{1}$ Chemistry, School of Natural and Environmental Sciences, Newcastle University, Newcastle upon Tyne NE1 7RU, UK

2 Current address: School of Chemistry, University of Edinburgh, Joseph Black Building, David Brewster Road, Edinburgh EH9 3FJ, UK

* Corresponding author's e-mail address: bill.clegg@ncl.ac.uk
}

RECEIVED: April 29, $2018 \star$ REVISED: June 6, 2018 ネ ACCEPTED: June 6, 2018

THIS PAPER IS DEDICATED TO DR. BISERKA KOJIĆ-PRODIĆ ON THE OCCASION OF HER 80Th BIRTHDAY

\begin{abstract}
Barbituric acid BAH reacts with potassium, rubidium and caesium iodides in methanol, forming anhydrous $\mathrm{BAH} \cdot \mathrm{MI}$. $\mathrm{BAH} \cdot \mathrm{CsI}$ has a different 8-fold coordination geometry from corresponding alkali metal bromides, intermediate between triangular dodecahedral and square antiprismatic. $\mathrm{BAH} \cdot \mathrm{KI}$ and $\mathrm{BAH} \cdot \mathrm{RbI}$ display features that are new for this family, with a high coordination number of 9 , and with no involvement of iodide in either coordination or hydrogen bonding, its environment being six $\mathrm{BAH}$ molecules. $\mathrm{BAH} \cdot \mathrm{NaCl} \cdot 2 \mathrm{H}{ }_{2} \mathrm{O}$, prepared by successive treatment of $\mathrm{BAH}$ in water with sodium hydroxide and dilute hydrochloric acid, is isostructural with other chlorides and bromides, with 7coordinate $\mathrm{Na}^{+}$and a network of hydrogen bonding. Two BAH molecules are oxidatively coupled by aqueous potassium permanganate to generate 5-hydroxyhydurilic acid, isolated as a hydrated potassium salt with $\mathrm{K}^{+}$in an unusually low 5-coordination. The folding of the $\mathrm{BAH}$ molecule in its full range of known crystal structures is analysed; the dihedral folding angle ranges from 0 to approximately $20^{\circ}$, uncorrelated with any other particular features of the structures.
\end{abstract}

Keywords: barbituric acid, alkali metals, crystal structure, cocrystals.

\section{INTRODUCTION}

$\mathbf{T}$ HERE is much interest in the topic of cocrystals, and a great deal of debate regarding how broadly they should be defined and what types of material are thereby encompassed (as well as whether the word cocrystal should be hyphenated!). The subject is by no means a purely semantic and academic one, because these definitions play a part in legal processes such as the patenting and licensing of new materials and chemical formulations, particularly in the pharmaceutical industry. A recent summary of the situation, with many authors from a range of institutions across the world, has proposed a broad definition that would probably be embraced readily by most scientific researchers in relevant fields: "cocrystals are solids that are crystalline single phase materials composed of two or more different molecular and/or ionic compounds generally in a stoichiometric ratio which are neither solvates nor simple salts". ${ }^{[1]}$ Cocrystal formation alters the physical and chemical properties of the components. Such modifications are the subject of research in its own right, and are also deliberate targets in the development and application of materials in pharmaceutical, commercial, industrial and other fields.

In 2010 Braga et al. reported the synthesis and structures of some complexes formed by a combination of alkali metal halide salts and the organic molecule barbituric acid (BAH), some with and others without water incorporated in the crystal structures; ${ }^{[2]}$ these were designated "ionic cocrystals" and fall within the broad definition of cocrystals given above. A later publication described further members of this family of compounds and the structural transformations involved in their hydration and dehydration reactions. ${ }^{[3]}$ Continuing interest in this area, with diverse applications including pharmaceuticals and nutrition, is illustrated by the recent appearance of a review Highlight covering the specific topic of organic-inorganic ionic cocrystals. ${ }^{[4]}$

Barbituric acid and its derivatives are excellent candidates for cocrystal studies because of their structural

(cc) Br 
simplicity, possibility of substitution at the $\mathrm{CH}_{2}$ and $\mathrm{NH}$ groups, and availability of several hydrogen bond donors and acceptors in such a small molecule. Although barbituric acid itself has no pharmaceutical applications, its derivatives with substituents at the saturated $\mathrm{C}$ atom are an extensive family known as barbiturates, with sedative, anti-depressant, anaesthetic and hypnotic properties. There are surprisingly few known crystal structures in which $\mathrm{BAH}$, without substitution or deprotonation at any of the ring atoms, is one of the components. Apart from the alkali metal halide ionic cocrystals mentioned above and two similar calcium halide ionic cocrystals, ${ }^{[5,6]}$ a search of the Cambridge Structural Database (version 5.39 with two updates, February 2018) finds only 21 structures together with polymorphs of BAH itself ${ }^{[7-9]}$ and its dihydrate. ${ }^{[10-12]}$ These include mainly cocrystals with various organic partners, ${ }^{[13-24]}$ a few structures containing both $\mathrm{BAH}$ and its anion $\mathrm{BA}^{-}$together with an organic or alkali metal cation, ${ }^{[25-27]}$ and an ionic cocrystal with the potassium salt of $\left[\mathrm{Pt}_{2} \mathrm{I}_{6}\right]^{2-}$.[28]

We have undertaken various structural studies of barbituric acid and related heterocyclic compounds such as violuric and cyanuric acid. These include a detailed variabletemperature investigation of an orthorhombic-monoclinic phase transition for barbituric acid dihydrate with particular reference to the extent to which the sixmembered ring of the BAH molecule deviates from planarity, ${ }^{[12]}$ a feature of interest in polymorph prediction studies of anhydrous BAH. ${ }^{[8]}$

Barbituric acid undergoes facile oxidative dimeric coupling to give 5-hydroxyhydurilic acid under a variety of conditions, both chemical and electrochemical, including atmospheric oxidation. We previously reported this as an unexpected reaction when attempting to prepare alkali metal complexes of the anion generated by deprotonation of barbituric acid, leading to two different polymorphs of a hydrated caesium complex. ${ }^{[29]}$ We have explored the possibility of similar reactions with other barbituric acid derivatives, ${ }^{[30]}$ and include here one product that is particularly relevant, a hydrated potassium complex of the 5-hydroxyhydurilate anion obtained by oxidation of barbituric acid with potassium permanganate, together with findings that extend the previously reported family of alkali metal halide ionic cocrystals of BAH and reveal some new structural features.

\section{EXPERIMENTAL SECTION}

All reagents were purchased from Aldrich, Lancaster Synthesis, Avocado, or Strem, and were used without further purification. The purity of the organic compounds used was verified by ${ }^{1} \mathrm{H}$ NMR spectroscopy. Methanol was dried over magnesium and stored over $3 \AA$ molecular sieves. Freshly distilled water was used for all aqueous syntheses.

Elemental analyses were carried out by the Newcastle University Advanced Chemical and Materials Analysis service. Single-crystal X-ray diffraction data were measured on Nonius KappaCCD and Oxford Diffraction Gemini A Ultra diffractometers ${ }^{[31,32]}$ at $150 \mathrm{~K}$ using MoKa radiation ( $\lambda=0.71073 \AA$ ). Semi-empirical absorption corrections were based on symmetry-equivalent reflections in the full datasets. ${ }^{[33]}$ The structures were solved by routine direct methods, and refined on all unique observed $F_{\mathrm{o}}{ }^{2}$ values, with programs of the SHELX family. ${ }^{[34,35]}$ Non- $\mathrm{H}$ atoms were refined anisotropically; all $\mathrm{H}$ atoms were refined freely with isotropic displacement parameters except for the twinned structure of compound $\mathbf{3}$, for which appropriate constraints were applied (the positions of the $\mathrm{N}$-bonded $\mathrm{H}$ atoms were refined freely, and for this structure soft restraints were also applied to the displacement parameters of $\mathrm{C}, \mathrm{N}$, and $\mathrm{O}$ atoms). The nonmerohedral twinning of $\mathbf{3}$ was identified during refinement as a $180^{\circ}$ rotation about the crystallographic $c$ axis, and the overlapping reflections were partitioned between the corresponding two components with subsequent refinement of the twin fraction to approximately 3:2. Crystallographic data and refinement details are summarised in Table 1, with full details in the Supplementary Material.

Synthesis of BAH.MI ( $\mathrm{M}=\mathrm{K}, \mathrm{Rb}, \mathrm{Cs}, 1-3): 0.13 \mathrm{~g}$ (1 $\mathrm{mmol}$ ) of BAH was dissolved in $10 \mathrm{~mL}$ methanol with gentle heating. $1 \mathrm{mmol}$ of $\mathrm{Ml}$ was added, giving a golden-brown solution. The sample vial was sealed and stored at room temperature for one week. Large colourless crystals were formed.

BAH·KI (1): $0.166 \mathrm{~g}$ (1 mmol) of K gave 1 (0.094 g, 32\%). Analysis, found: C 26.41, H 2.11, N 15.36\%; calc C 26.17, H 2.18, N $15.26 \%$.

BAH·Rbl (2): $0.221 \mathrm{~g}$ (1 mmol) of Rbl gave 2 (0.121 g, 35\%). Analysis, found: C 24.17, H 2.10, N 13.82\%; calc C 24.16, H $2.03, \mathrm{~N} 14.01 \%$.

BAH.CsI (3): $0.264 \mathrm{~g}(1 \mathrm{mmol})$ of Csl gave $3(0.121 \mathrm{~g}, 30 \%)$. Analysis, found: C 13.06, H 0.88, N 7.06\%; calc C 13.37 , H 1.03, N 7.20\%.

Synthesis of $\mathrm{BAH} \cdot \mathrm{NaCl} \cdot 2 \mathrm{H}_{2} \mathrm{O}(4): 0.13 \mathrm{~g}(1 \mathrm{mmol})$ of $\mathrm{BAH}$ and $0.40 \mathrm{~g}(1 \mathrm{mmol})$ of $\mathrm{NaOH}$ were dissolved in $30 \mathrm{~mL}$ water and the volume reduced by approximately half by heating. Dilute hydrochloric acid ( $1 \mathrm{mmol}$ ) was added. The sample vial was sealed and stored at room temperature overnight. Colourless crystals of $\mathbf{4}$ were formed $(0.079 \mathrm{~g}$, $36 \%)$. Analysis, found: C 13.29, H 3.58, N 12.48\%; calc C 13.37, H 3.62, N $12.59 \%$.

Synthesis of $\mathrm{K}^{+}\left(\right.$hydroxyhydurilate $\left.{ }^{-}\right) \cdot \mathrm{H}_{2} \mathrm{O}(\mathbf{5}): 0.132 \mathrm{~g}$ $(1 \mathrm{mmol})$ of $\mathrm{BAH}$ was dissolved in $20 \mathrm{~mL}$ water and heated 
Table 1. Crystal data and summary of refinements

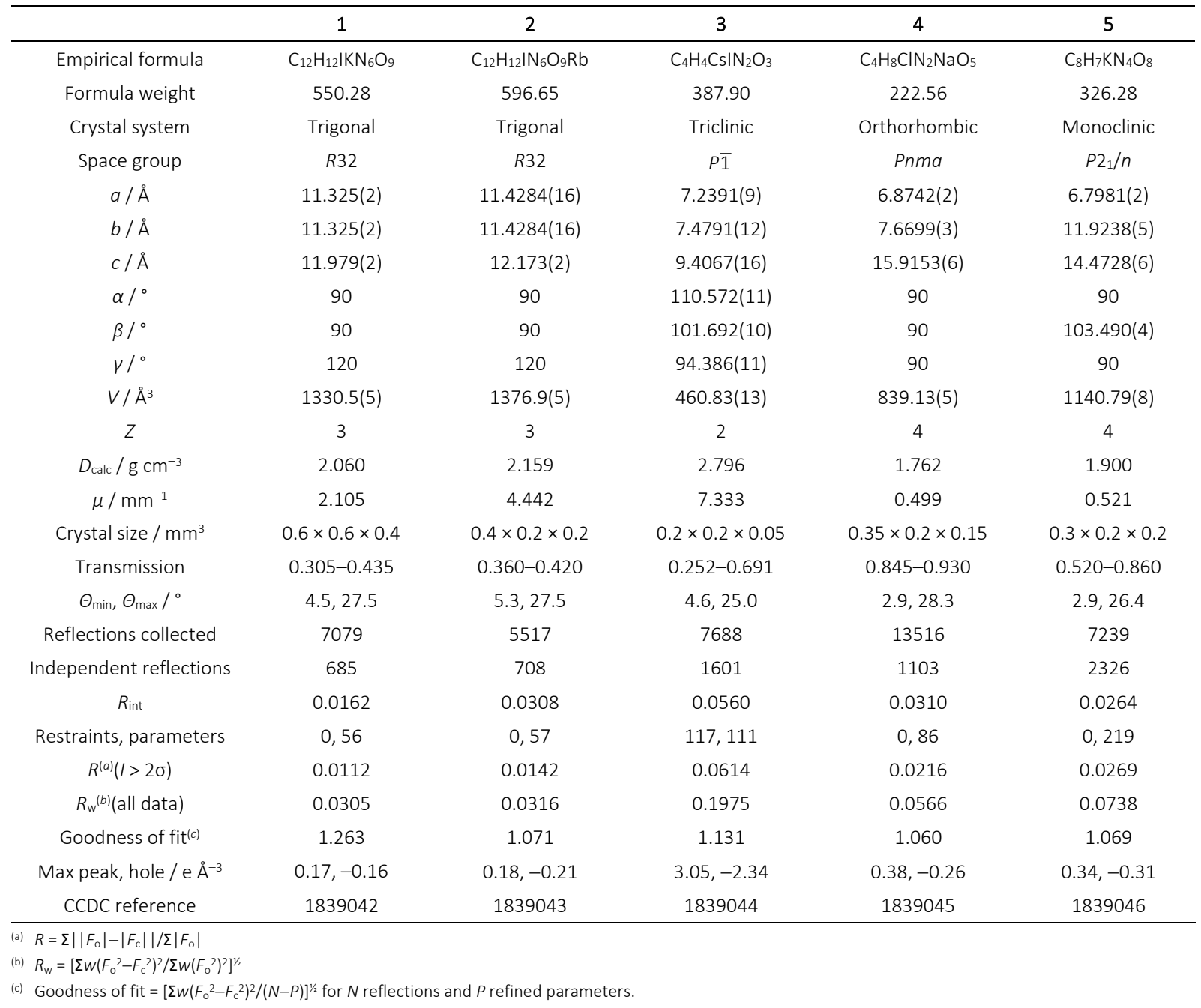

to boiling. $0.60 \mathrm{~g}$ ( $3.8 \mathrm{mmol}$ ) of $\mathrm{KMnO}_{4}$ in $30 \mathrm{~mL}$ warm water was added slowly and boiling continued for $10 \mathrm{~m}$. The hot solution was filtered to remove precipitated $\mathrm{MnO}_{2}$, and the filtrate was acidified to $\mathrm{pH}=6$ with dilute hydrochloric acid. The solution was evaporated to dryness and the product extracted with $20 \mathrm{~mL}$ hot water. The filtered solution was covered and left undisturbed overnight. Pale yellow crystals of $\mathbf{5}$ were formed $(0.044 \mathrm{~g}, 27 \%)$. Analysis, found: C 29.78, H 2.20, N 17.35 \% calc. C 29.45, H 2.16, N $17.17 \%$.

\section{RESULTS AND DISCUSSION}

We have synthesised 1:1 ionic cocrystals of barbituric acid with the three heavier alkali metal iodides $\mathrm{KI}, \mathrm{Rbl}$, and $\mathrm{Csl}$ and with sodium chloride. In a related experiment oxidative coupling of barbituric acid has generated a hydrated potassium complex of the hydroxyhydurilic acid anion. The syntheses are straightforward and require no further comment.

\section{Structures of 1-3}

The three alkali metal iodide cocrystals are all anhydrous; the presence of water was deliberately avoided by carrying out the syntheses in dry methanol as solvent. Of these products, the Csl compound has been reported previously, ${ }^{[2]}$ and our own structural result is essentially the same, although the crystal investigated here proved to be twinned; it is, therefore, not discussed in detail except for one aspect. It has a different crystal structure (with the triclinic space group $P \overline{1}$ ) from any of the known anhydrous $\mathrm{MBr}$ bromide cocrystals of barbituric acid ( $\mathrm{M}=\mathrm{Na}, \mathrm{K}, \mathrm{Rb}$, $\mathrm{Cs}$ ), each of which has a distinct crystal structure in a monoclinic space group except that $\mathrm{BAH} \cdot \mathrm{RbBr}$ is isostructural with $\mathrm{BAH} \cdot \mathrm{CsBr} .{ }^{[2,3]}$ One feature of the $\mathrm{BAH} \cdot \mathrm{Csl}$ structure that has not previously been noted is the geometry of the 8-fold coordination of $\mathrm{Cs}^{+}$by five $\mathrm{BAH} \mathrm{O}$ atoms and three $\mathrm{I}^{-}$anions (each of which is connected to three cations). A coordination number of 8 is found for the 
series of anhydrous bromide cocrystals with the exception of $\mathrm{BAH} \cdot \mathrm{NaBr}$, where the small $\mathrm{Na}^{+}$cation has a 6 -fold octahedral coordination. The 8-coordinate geometry has been described in each case as bicapped trigonal prismatic. ${ }^{[2,3]}$ To assess the geometry we have used the approach of Porai-Koshits and Aslanov, ${ }^{[36]}$ further developed for other coordination numbers by Muetterties and Guggenberger, ${ }^{[37]}$ in which dihedral angles between pairs of polyhedral faces are used to characterise and distinguish among the recognised regular coordination polyhedra, particularly the triangular dodecahedron, bicapped trigonal prism, and square antiprism. The analysis is simplified by normalising the coordination bond lengths to be equal while maintaining the experimentally observed bond angles, so that the relevant polyhedral edges are more readily identified. In the notation of Porai-Koshits and Aslanov, the four pertinent dihedral angles $\delta$ are all $29.5^{\circ}$ for an ideal triangular dodecahedron; 0, 21.7 and $2 \times 48.2^{\circ}$ for an ideal bicapped trigonal prism; and $2 \times 0$ and $2 \times 52.5^{\circ}$ for an ideal square antiprism, with all vertices equidistant from the centre of the polyhedron in each case. As a representative of the anhydrous bromides and for direct comparison with the BAH.CsI structure, we find for $\mathrm{BAH} \cdot \mathrm{CsBr} \delta$ values of $4.1,21.8,45.4$ and $53.6^{\circ}$, which are indeed close to those for bicapped trigonal prismatic coordination; similar results are obtained for the other bromides ( $\mathrm{K}$ and $\mathrm{Rb}$ ). The corresponding values for $\mathrm{BAH} \cdot \mathrm{Csl}$ are $11.5,12.4,41.7$ and $49.7^{\circ}$; this represents a geometry intermediate between triangular dodecahedral and square antiprismatic and somewhat closer to the latter, as shown in Figure 1. It differs significantly from the bicapped trigonal prismatic geometry observed in the 8-coordinate anhydrous bromides.

The two new anhydrous iodide cocrystals with $\mathrm{KI}$ and Rbl (1 and 2, respectively) form an isostructural pair, but this structure is very different from that of the Csl cocrystal. Indeed, there are a number of structural features that strongly distinguish these two compounds from the Csl and all the bromide compounds. The one common feature of all seven structures is that every barbituric acid $\mathrm{O}$ atom is involved in direct coordination to alkali metal cations.

The first major difference for the $\mathrm{KI}$ and $\mathrm{RbI}$ compounds is that the halide anion does not coordinate to any metal ions, nor does it serve as a hydrogen bond acceptor. These structures are of high crystallographic symmetry, with the $\mathrm{M}^{+}$cations and $\mathrm{I}^{-}$anions each lying on the intersection of a threefold and three twofold rotation axes at a site with point-group symmetry $32\left(D_{3}\right)$; a twofold rotation axis passes through the barbituric acid molecule. The iodide anion is surrounded and completely enclosed by six BAH molecules, which form the faces of an approximate cube, as shown in Figure 2; the distance between the anion and each ring centroid is 3.840(2) $\AA$ in 1 and 3.880(2) $\AA$ in

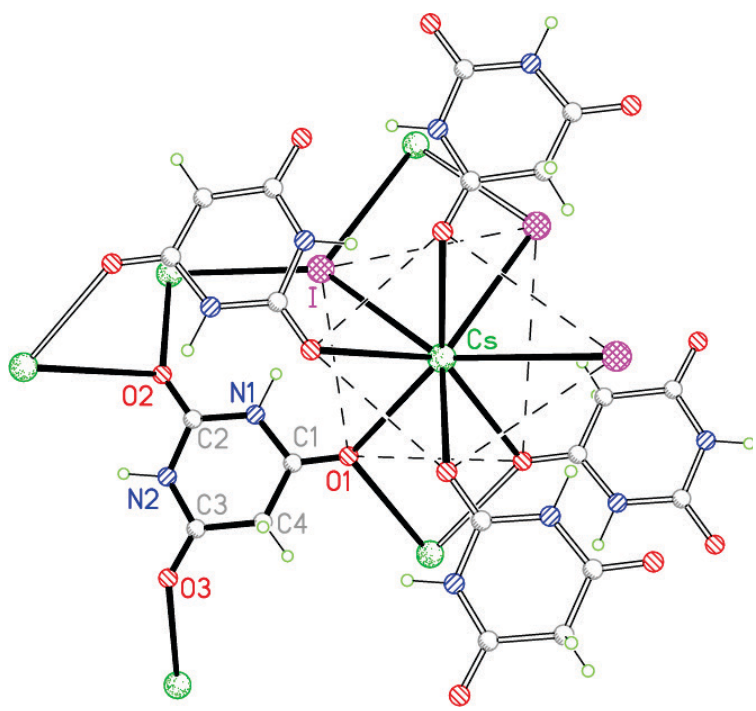

Figure 1. The asymmetric unit of 1 together with symmetryequivalent cations, anions and BAH molecules sufficient to complete its environment. Bonds to the labelled atoms of the asymmetric unit are shown filled, others are open, bonds to $\mathrm{H}$ atoms are single lines. Hydrogen bonding is not shown. The dashed lines indicate the upper and lower quadrilateral faces of the square antiprismatic coordination of Cs.

2. The shortest $M \cdots \cdot$ I distance is 5.990 (1) $\AA$ in $\mathbf{1}$ and 6.086(1) $\AA$ in 2. This contrasts with the anhydrous bromide and CsI structures, in which the halide anions bridge two ( $\mathrm{Na}$ and $\mathrm{K})$ or three ( $\mathrm{Rb}$ and $\mathrm{Cs}$ ) cations.

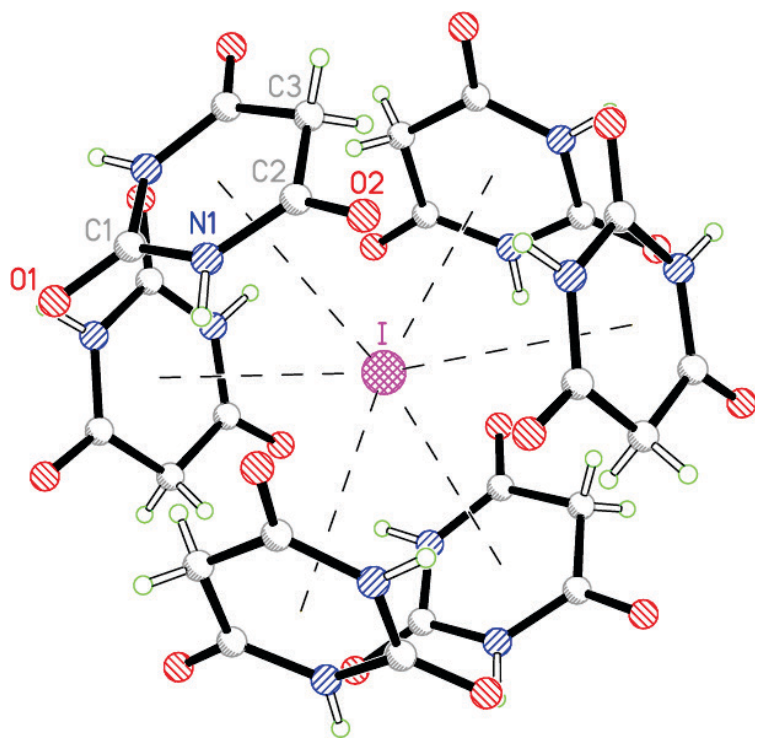

Figure 2. One iodide anion of 2 with its six surrounding $\mathrm{BAH}$ molecules, the centroids of which are connected to the anion by dashed lines. The atoms of the asymmetric unit are labelled; the cation is not shown. 


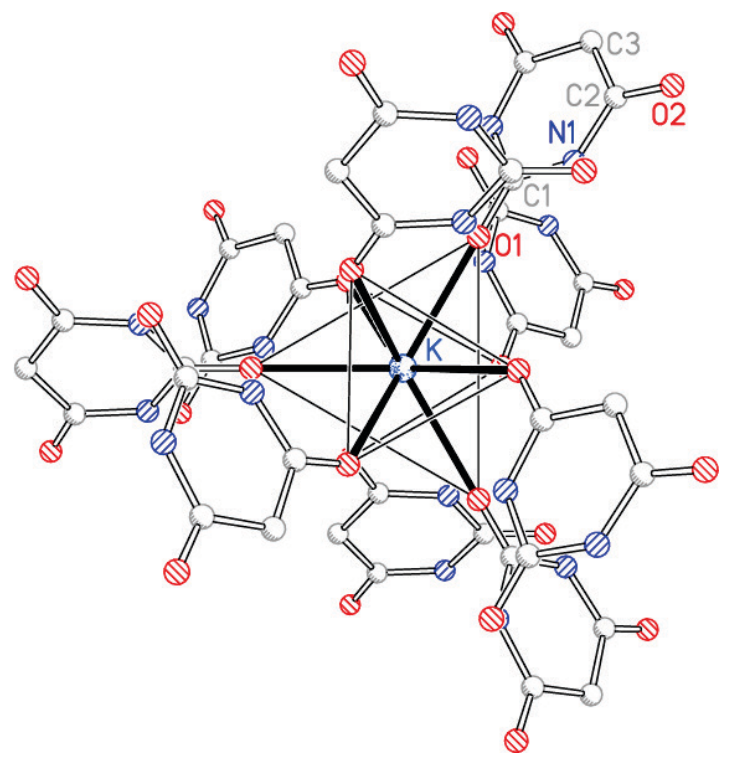

Figure 3. The nine-coordinate arrangement of BAH molecules around the $\mathrm{K}^{+}$cation of 2 . The three triangles indicate the eclipsed upper and lower prismatic faces and the staggered equatorial ligands. Atoms of the asymmetric unit are labelled; the anion is not shown.

Secondly, the metal coordination number of 9 is the highest in the whole series of anhydrous and hydrated ionic cocrystals, the range in previously reported structures being $6-8$. Coordination of $\mathrm{K}^{+}$or $\mathrm{Rb}^{+}$is exclusively by $\mathrm{BAH} \mathrm{O}$ atoms. Three symmetry-equivalent urea-like carbonyl atoms $\mathrm{O} 1 \mathrm{form}$ an equilateral triangle in an equatorial plane, while six symmetry-equivalent carboxamide atoms $\mathrm{O} 2$ are arranged in equilateral triangles above and below the equatorial plane, these two triangles being almost perfectly eclipsed relative to each other and staggered with respect to the equatorial triangle, as shown in Figure 3. The coordination geometry is thus an essentially ideal tricapped trigonal prism with capping of all three rectangular faces. The unique $\mathrm{K}-\mathrm{O} 2$ distance of $2.942(2) \AA$ is markedly longer than the unique $\mathrm{K}-\mathrm{O} 1$ distance of 2.753(2) $\AA$ in 1, and the shortest $\mathrm{O} \cdots \mathrm{O}$ distances in the coordination polyhedron are 3.272(2)-3.362(2) $\AA$, with O-K-O angles of 69.69(5)-71.44(3) \% corresponding distances for 2 are $\mathrm{Rb}-\mathrm{O} 2$ 3.022(2), $\mathrm{Rb}-\mathrm{O} 1$

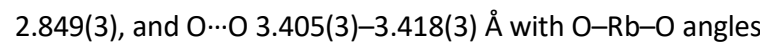
of $68.87(6)-71.06(4)^{\circ}$, reflecting the larger ionic radius of $\mathrm{Rb}^{+}$.

Hydrogen bonding in $\mathbf{1}$ and $\mathbf{2}$ is restricted to $\mathrm{N}-\mathrm{H} \cdots \mathrm{O}$ interactions between $\mathrm{BAH}$ molecules, with no involvement of $\mathrm{I}^{-}$anions. Each $\mathrm{N}-\mathrm{H}$ bond donates a hydrogen bond to an $\mathrm{O} 2$ atom; $\mathrm{O} 1$ does not function as an acceptor. The hydrogen atoms connect the BAH molecules to form a sheet perpendicular to the $c$ axis, as shown in Figure 4 . These sheets are linked by the $\mathrm{K}-\mathrm{O} 2$ bonds above and below the equatorial plane to give the complete threedimensional coordination network structure.

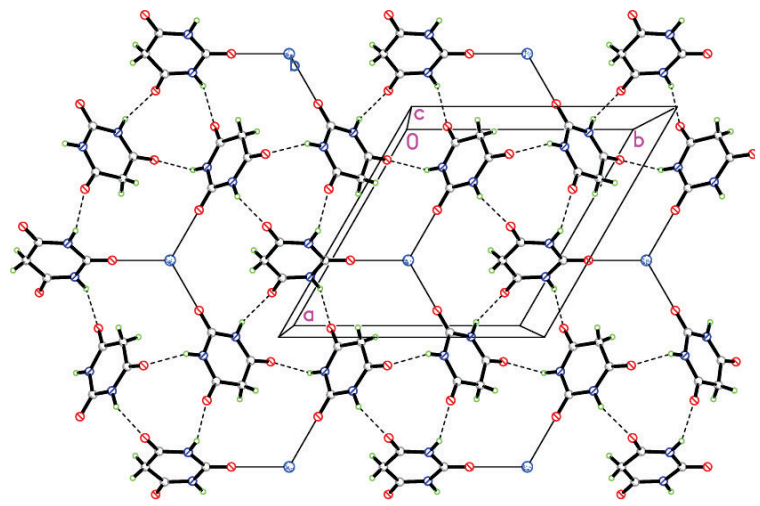

Figure 4. A hydrogen-bonded sheet of BAH molecules in the structure of 2 (and 3 ).

\section{Structure of 4}

The hydrated cocrystals $\mathrm{BAH} \cdot \mathrm{MX} \cdot 2 \mathrm{H}_{2} \mathrm{O}$ have previously been characterised structurally for the bromides $\mathrm{NaBr}, \mathrm{KBr}$, and $\mathrm{RbBr}$, and for the chloride $\mathrm{KCl}$, and some features of the structure have been briefly described; they are all isostructural. ${ }^{[2,38]}$ Our work here adds the $\mathrm{NaCl}$ compound to the family, and it is also isostructural. The cation, anion and BAH molecule all lie on a crystallographic mirror plane. The alkali metal cation is 7-coordinate, with a mono-capped trigonal prismatic geometry, one rectangular prism face being capped by a urea-like $\mathrm{BAH} \mathrm{O}$ atom. Each triangular face of the prism is formed by two water $\mathrm{O}$ atoms and one carboxamide $\mathrm{BAH} \mathrm{O}$ atom, and the two triangular faces are perfectly eclipsed as they are equivalent by mirror symmetry, the capping $\mathrm{O}$ atom and the cation lying in the mirror plane. Each water molecule bridges two cations and donates $\mathrm{O}-\mathrm{H} . . . \mathrm{Cl}$ hydrogen bonds to two anions. Each anion serves as an acceptor of four hydrogen bonds from water molecules and two from $\mathrm{BAH} \mathrm{N-H}$ groups; the anions do not participate in coordination of the cations. There are no $\mathrm{N}-\mathrm{H} \cdots \mathrm{O}$ hydrogen bonds. In sequence along the crystallographic $c$ axis layers of BAH molecules alternate with layers containing the cations, anions and water molecules. Principal features of the structure are illustrated in Figure 5.

\section{Structure of 5}

The asymmetric unit of the crystal structure of $\mathbf{5}$ contains one $\mathrm{K}^{+}$cation, one 5-hydroxyhydurilate anion $\left(\mathrm{HH}^{-}\right)$, and one water molecule (Figure 6). The formal site of deprotonation of 5-hydroxyhydurilic acid is the C5' position (labelled C8 in Figure 6) to give a trigonal planar centre, as for barbituric acid itself, but the negative charge is delocalised over the adjacent carbonyl groups. All three carbonyl $\mathrm{O}$ atoms of this deprotonated ring and the urealike carbonyl $\mathrm{O}$ atom of the other ring are involved in coordination of $\mathrm{K}^{+}$cations. Consistent with the stoichiometry, the unique cation is coordinated by carbonyl $O$ 


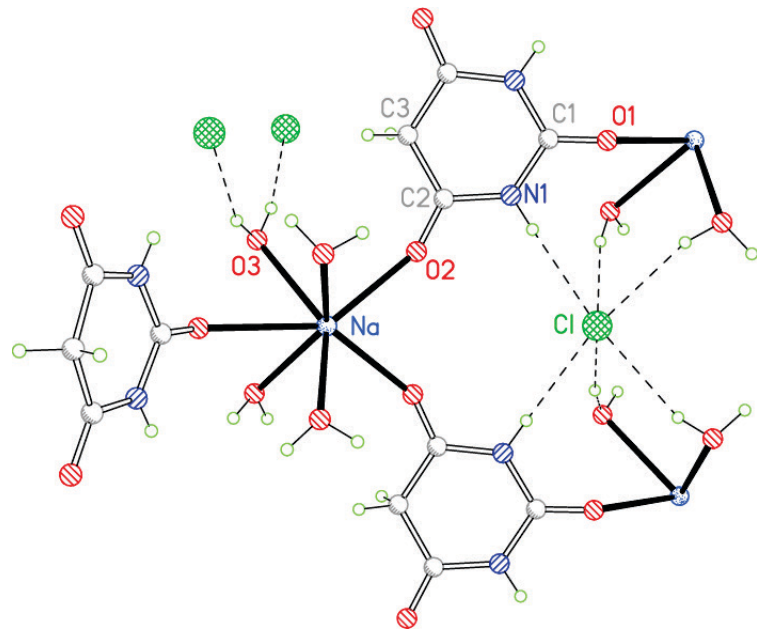

Figure 5. A section of the crystal structure of 4 , showing the labelled atoms of the asymmetric unit together with its complete environment (coordination and hydrogen bonding). The crystallographic mirror planes are almost edge-on in this view and run horizontally across the Figure. Hydrogen bonds are shown as dashed lines.

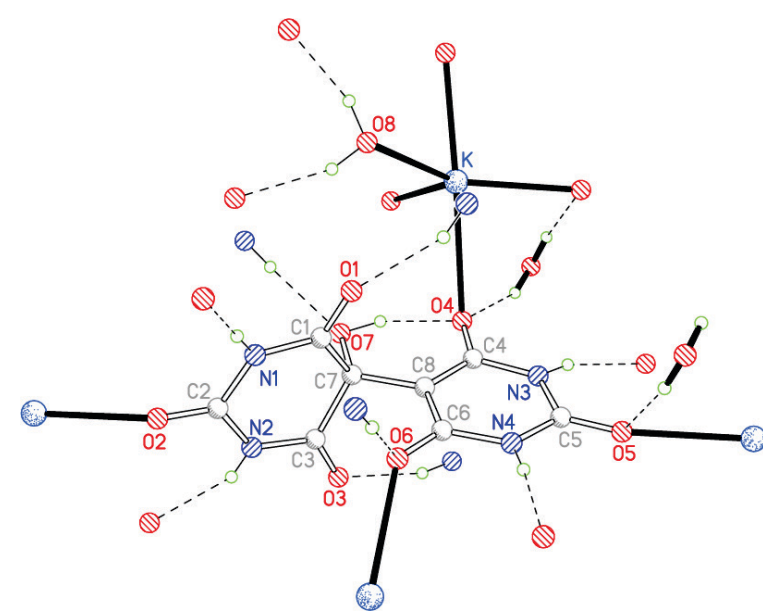

Figure 6. The labelled asymmetric unit of 5 together with additional atoms to complete its coordination and hydrogen-bonding environment.

atoms of four different $\mathrm{HH}^{-}$anions together with one water molecule, giving a rather low coordination number of 5 . The coordination geometry is intermediate between trigonal bipyramidal $(\tau=1)$ and square-based pyramidal $(\tau=0)$, with a structural parameter $\tau$ of 0.56 according to the formulation of Addison et al.; ${ }^{[39]}$ the water molecule lies in an equatorial/basal position. The coordination network is three-dimensional and dense, and is further supported by an extensive three-dimensional arrangement of hydrogen bonds in which all four $\mathrm{N}-\mathrm{H}$ groups and both water $\mathrm{O}-\mathrm{H}$ bonds serve as donors to $\mathrm{O}$ atoms of other $\mathrm{HH}^{-}$ anions; all but one carbonyl $\mathrm{O}$ atoms function as acceptors, the exception being 02 . The hydroxy group accepts an $\mathrm{N}-\mathrm{H} \cdots \mathrm{O}$ hydrogen bond and forms an intramolecular $\mathrm{O}-\mathrm{H} \cdots \mathrm{O}$ hydrogen bond with $\mathrm{O} 4$ of the same anion. The water $\mathrm{O}$ atom does not function as a hydrogen bond acceptor. Full details of the hydrogen bonding are provided in the Supplementary Material. Many of the features of the metal ion coordination and hydrogen bonding in this structure are thus similar to those in the barbituric acid ionic cocrystal family, the major differences being the relatively low coordination number of $\mathrm{K}^{+}$and the absence of a halide anion.

The 5-hydroxyhydurilate anion has been reported as a component in only six crystal structures previously. Two of these are polymorphs of the hydrated caesium complex $\mathrm{Cs}^{+} \mathrm{HH}^{-} \cdot 0.5 \mathrm{H}_{2} \mathrm{O}$, both of which are three-dimensional coordination networks with 9-coordinate $\mathrm{Cs}^{+}$, and contain water molecules that are hydrogen bonded but not coordinated. ${ }^{[29]}$ Only one other structure has $\mathrm{HH}^{-}$as a coordinated ligand, and this is a discrete mononuclear fourcoordinate copper(II) complex $\left[\left(2,2^{\prime}\right.\right.$-bipy $\left.) \mathrm{Cu}(\mathrm{HH})\right] \cdot 3 \mathrm{H}_{2} \mathrm{O}$ in which the ligand is bidentate and chelating. ${ }^{[40]}$ In the other known crystal structures $\mathrm{HH}^{-}$is an uncoordinated anion charge-balanced by either a mononuclear manganese(II) complex cation or an organic cation, and the structure also incorporates water or DMF solvent molecules, with extensive hydrogen bonding. ${ }^{[41,42]}$

\section{Conformation of the Barbituric Acid Six-membered Ring}

The final point of structural interest for these compounds is the extent to which the barbituric acid six-membered ring is non-planar, with the $\mathrm{CH}_{2}$ group displaced from the mean plane of the other five conjugated atoms. A convenient quantitative measure of this non-planarity is the envelope dihedral angle between the five-atom mean plane and the three-atom flap consisting of the $\mathrm{CH}_{2}$ carbon atom and the two carbonyl $\mathrm{C}$ atoms to which it is bonded, defined such that a dihedral angle of 0 denotes planarity of the ring. The first reported crystal structure of anhydrous barbituric $\operatorname{acid}^{[7]}$ at room temperature has a dihedral angle of $13.8^{\circ}$, with $14.1^{\circ}$ in a later redetermination at $150 \mathrm{~K},{ }^{[7]}$ but another polymorph gives $8.2^{\circ},{ }^{[9]}$ and a further polymorph at $150 \mathrm{~K}$ contains two molecules in the asymmetric unit with the markedly different values of 1.2 and $22.4^{\circ}$, representing one essentially planar and one distinctly folded conformation. ${ }^{[8]}$ This particular polymorph was also the subject of crystal structure prediction, which indicated the same result. However, close examination of the atomic displacement parameters suggests the possibility that the observed planar form is a consequence of unresolved disorder for a folded form in two orientations. The original $X-$ ray $^{[10]}$ and neutron ${ }^{[11]}$ single-crystal diffraction studies of barbituric 
acid dihydrate $\mathrm{BAH} \cdot 2 \mathrm{H}_{2} \mathrm{O}$ at room temperature locate all the ring atoms on a crystallographic mirror plane in the orthorhombic space group Pnma, so the ring is necessarily exactly planar. However, a redetermination at $150 \mathrm{~K}$ indicated a twinned structure in the monoclinic space group $P 2_{1} / n$, in which the mirror plane is absent; ${ }^{[12]}$ the unit cell parameters are similar and the lower-symmetry lowtemperature structure is clearly the consequence of a phase transition on cooling. We carried out a detailed examination of this structural change with data collections at a range of temperatures, and concluded that the ring becomes non-planar on cooling through the transition point, with a dihedral angle reaching $8.2^{\circ}$ at $100 \mathrm{~K}$. The water molecules in this structure, coplanar with the acid molecule in the orthorhombic room-temperature form, are displaced significantly out of this plane in the low-temperature form. ${ }^{[12]}$

This degree of ring flexibility found in the various polymorphs of barbituric acid and its dihydrate is exhibited across the approximately 20 known crystal structures in which $\mathrm{BAH}$ is a component (other than the alkali metal halide cocrystals discussed in this paper), both coordinated to metal ions and uncoordinated in various salts and cocrystals: dihedral angles range from 0.4 to $24.8^{\circ}$, with a mean of $6.4^{\circ}$ and a large majority between 0 and $10^{\circ}$. For 12 of the 14 anhydrous and hydrated $\mathrm{BAH}-\mathrm{MX}$ structures there is a rather narrower range of $9.1-19.9^{\circ}$ at the upper end of the total observed range. The outstanding exceptions are the high-symmetry $\mathrm{KI}$ and Rbl structures $\mathbf{1}$ and $\mathbf{2}$ reported here for the first time, which have dihedral angles of $0.4(2)$ and $0.1(3)^{\circ}$ respectively, so the BAH ring is essentially planar in these structures, in marked contrast to the others in the series. These are very precise structures with no suggestion of possible disorder, the anisotropy of the saturated $\mathrm{C}$ atoms being no more than that of the carbonyl $\mathrm{O}$ atoms, so this is another unusual feature of the two iodide complexes within the family of compounds.

The hydurilic acid anion $\mathrm{HH}^{-}$has two six-membered rings, one of which electronically resembles the deprotonated barbiturate anion $\mathrm{BA}^{-}$and is essentially planar in all the crystal structures in which $\mathrm{HH}^{-}$appears, as a consequence of delocalisation; the other retains the electronic structure of $\mathrm{BAH}$ itself, with substitution of both $\mathrm{H}$ atoms of the $\mathrm{CH}_{2}$ group by hydroxy and by the $\mathrm{BA}^{-}$ring. The envelope dihedral angle for this ring is $17.6(1)^{\circ}$ in $\mathbf{5}$ and lies in the range $6.2-19.6^{\circ}$ in the other known structures. ${ }^{[29,40-42]}$

\section{CONCLUSIONS}

Barbituric acid, a small molecule with a plethora of coordination and hydrogen bonding sites, lends itself well to a range of supramolecular interactions and is a strong candidate for generating cocrystals. The formation of ionic cocrystals of barbituric acid with alkali metal halides, already well established with numerous examples, is here extended with new family members. Some of these reinforce previously observed behaviour, but there are also new structural features, including a high coordination number of 9 for potassium and rubidium cations and the failure of iodide to engage in coordination or hydrogen bond formation in two of the examples. The flexibility of the barbituric acid molecule in terms of folding of the $\mathrm{CH}_{2}$ group out of the ring plane is found to be small but varied, and does not seem to be strongly correlated with other aspects of the crystal structures in which this molecule is found.

Acknowledgment. We thank Newcastle University for financial support, EPSRC (UK) and GlaxoSmithKlyne for partial funding of X-ray crystallographic equipment, and Dr Neil Brooks for assistance with the twinning treatment.

Supplementary Information. CCDC 1839042-1839046 contain the supplementary crystallographic data for this contribution. These data can be obtained free of charge via www.ccdc.cam.ac.uk/conts/retrieving.html (or from the Cambridge Crystallographic Data Centre, 12 Union Road, Cambridge CB2 1EZ, UK; fax: (+44) 1223-336-033; or deposit@ccdc.ca.ac.uk.

\section{REFERENCES}

[1] S. Aitipamula, R., A. K. Bansal, K. Biradha, M. L. Cheney, A. R. Choudhury, G. R. Desiraju, A. G. Dikundwar, R. Dubey, N. Duggirala, P. P. Ghogale, S. Ghosh, P. K. Goswami, N. R. Goud, R. K. R. Jetti, P. Karpinski, P. Kaushik, D. Kumar, V. Kumar, B. Moulton, A. Mukherjee, G. Mukherjee, A. S. Myerson, V. Puri, A. Ramanan, T. Rajamannar, C. M. Reddy, N. Rodriguez-Hornedo, R. D. Rogers, T. N. Guru Row, P. Sanphui, N. Shan, G. Shete, A. Singh, C. C. Sun, J. A. Swift, R. Thaimattam, T. S. Thakur, R. K. Thaper, S. P. Thomas, S. Tothadi, V. R. Vangala, P. Vishweshwar, D. R. Weyna, M. J. Zaworotko, Cryst. Growth Des. 2012, 12, 2147; 2012, 12, 4290.

[2] D. Braga, F. Grepioni, L. Maini, S. Prosperi, R. Gobetto, M. R. Chierotti, Chem. Commun. 2010, 46, 7715.

[3] L. Maini, D. Braga, F. Grepioni, G. I. Lampronti, K. Gaglioti, R. Gobetto, M. R. Chierotti, CrystEngComm 2016, 18, 4651.

[4] D. Braga, F. Grepioni, O. Shemchuk, CrystEngComm 2018, 20, 2212.

[5] D. Braga, F. Grepioni, G. I. Lampronti, L. Maini, A. Turrina, Cryst. Growth Des. 2011, 11, 5621.

[6] D. Braga, F. Grepioni, L. Maini, G. I. Lampronti, D. Capucci, C. Cuocci, CrystEngComm 2012, 14, 3521. 
[7] W. Bolton, Acta Crystallogr. 1963, 16, 166.

[8] T. C. Lewis, D. A. Tocher, S. L. Price, Cryst. Growth Des. 2004, 4, 979.

[9] D. M. Tobbens, J. Glinnerman, M. R. Chierotti, J. van de Streek, D. Sheptyakov, CrystEngComm 2012, 14, 3046.

[10] G. A. Jeffrey, S. Ghose, J. O. Warwicker, Acta Crystallogr. 1961, 14, 881.

[11] A. R. Al-Karaghouli, B. Abdul-Wahab, E. Ajaj, S. AlAsaff, Acta Crystallogr., Sect. B 1977, 33, 1655.

[12] G. S. Nichol, W. Clegg, Acta Crystallogr., Sect. B 2005, 61, 464.

[13] M. Gryl, A. Krawczuk, K. Stadnicka, Acta Crystallogr., Sect. B 2008, 64, 623.

[14] M. Gryl, A. Krawczuk-Pantula, K. Stadnicka, Acta Crystallogr., Sect. B 2011, 67, 144.

[15] S. Al-Saqqar, L. R. Falvello, T. Soler, J. Chem. Crystallogr. 2004, 34, 61.

[16] J.-M. Chen, S. Li, T.-B. Lu, Cryst. Growth Des. 2014, 14, 6399.

[17] P. T. Muthiah, M. Hemamalini, G. Bocelli, A. Cantoni, Struct. Chem. 2007, 18, 171.

[18] G. S. Nichol, W. Clegg, Cryst. Growth Des. 2009, 9, 1844.

[19] O. Shemchuk, D. Braga, F. Grepioni, Chem. Commun. 2016, 52, 11815.

[20] M. Du, Z.-H. Zhang, X.-J. Zhao, Cryst. Growth Des. 2006, 6, 390.

[21] L. S. Reddy, N. J. Babu, A. Nangia, Chem. Commun. 2006, 1369.

[22] B. B. Ivanova, M. Spiteller, Cryst. Growth Des. 2010, 10, 2470.

[23] S. Kumaresan, CSD Communication 2015; Refcode UHUGAH.

[24] N. J. Babu, L. S. Reddy, A. Nangia, Mol. Pharmaceutics 2007, 4, 417.
[25] Z.-H. Zhang, Q. Zhang, Q.-Q. Zhang, C. Chen, M.-Y. He, Q. Chen, G.-Q. Song, X.-P. Xuan, X.-F. Huang, Acta Crystallogr., Sect. B 2015, 71, 437.

[26] M. Gryl, K. Stadnicka, Acta Crystallogr., Sect. E 2011, 67, m571.

[27] M. R. Chierotti, K. Gaglioti, R. Gobetto, D. Braga, F. Grepioni, L. Maini, CrystEngComm 2013, 15, 7598.

[28] J. Martin-Gil, F. J. Martin-Gil, M. Perez-Mendez, J. Fayos, Z. Kristallogr. 1985, 173, 179.

[29] COLLECT software, Enraf-Nonius BV, Delft, The Netherlands, 2008.

[30] CrysAlisPro software, Oxford Diffraction, Oxford, UK, 2008.

[31] SADABS, G. M. Sheldrick, University of Göttingen, Germany, 2010.

[32] G. M. Sheldrick, Acta Crystallogr. Sect. A 2008, 64, 112.

[33] G. M. Sheldrick, Acta Crystallogr. Sect. C 2015, 71, 3.

[34] M. A. Porai-Koshits, L. A. Aslanov, Zh. Strukt. Khim. 1972, 13, 266.

[35] E. L. Muetterties, L. J. Guggenberger, J. Am. Chem. Soc. 1974, 96, 1748

[36] X. Huang, C. Cui, CSD Communication 2016; Refcode BANLUA.

[37] G. S. Nichol, W. Clegg, Acta Crystallogr., Sect. C 2005, 61, m459.

[38] W. Clegg, K. Guille, G. S. Nichol, unpublished results.

[39] A. W. Addison, T. Nageswara Rao, J. Reedijk, J. van Rijn, G. C. Verschoor, J. Chem. Soc. Dalton Trans. 1984, 1349.

[40] N. Dixit, R. K. Koiri, B. K. Maurya, S. K. Trigun, C. Hobartner, L. Mishra, J. Inorg. Biochem. 2011, 105, 256.

[41] H. C. Garcia, M. T. C. Campos, H. G. M. Edwards, L. F. C. de Oliveira, Vibr. Spect. 2016, 86, 134.

[42] T. Koike, Y. Yasu, M. Akita, Chem. Lett. 2012, 41, 999. 